\title{
CHEMICAL REACTIONS AND ELECTRONIC FUNCTIONS OF CARBON CLUSTER ARRAYS STUDIED BY SCANNING TUNNELING SPECTROSCOPY AND HIGH-RESOLUTION ELECTRON ENERGY LOSS SPECTROSCOPY
}

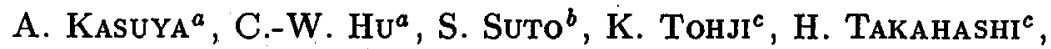 \\ R. CZAJKA ${ }^{d}, \mathrm{~A}$. WAWRO ${ }^{e}$ AND Y. NISHINA ${ }^{a}$ \\ anstitute for Materials Research, Tohoku University, Sendai 980-77, Japan \\ ${ }^{b}$ Department of Physics, Tohoku University, Sendai 980-77, Japan \\ ${ }^{c}$ Department of Geo-Science and Technology, Tohoku University, Sendai 980-77, Japan \\ ${ }^{d}$ Institute of Physics, Poznan University of Technology, Poznan, Poland \\ ${ }^{e}$ Institute of Physics, Polish Academy of Sciences, Warsaw, Poland
}

Novel nanometer scale structures have been produced by thermal heating or laser irradiation on the surface of single- and multi-layers of $\mathrm{C}_{60}$ and $\mathrm{C}_{84}$ on $\mathrm{Si}$. These structures were examined by combined measurements of scanning tunneling spectroscopy and high resolution electron energy loss spectroscopy. The results show specific chemical reactions of substrate with carbon clusters having single- and double-bonded network. Covalent bonds are formed in some of these chemical reactions.

PACS numbers: $61.16 . \mathrm{Ch}, 61.14 . \mathrm{Rq}, 73.61 . \mathrm{Wp}$

\section{Introduction}

Microcluster is a nanometer size particle consisting of several to thousands of atoms chemically bonded together. It exhibits strong size dependent properties which can be found in neither atomic phase nor solid. Arrays of microclusters produce a variety of nano-structures in their arrangements and show unique electronic functions for possible device applications. This paper presents the formation of such novel nano-structures by heating and laser irradiation on the arrays of carbon microclusters, $\mathrm{C}_{60}$ and $\mathrm{C}_{84}$.

Chromatographically separated $\mathrm{C}_{60}$ and $\mathrm{C}_{84}$ were evaporated on $\mathrm{Si}(100)$ or (111) surface in vacuum and their ordering structures and electronic properties were analyzed by a combined in-situ measurement of scanning tunneling spectroscopy (STS) and high-resolution electron energy loss spectroscopy (HREELS) in ultra-high vacuum [1-3]. 


\section{Mono-layer of $\mathrm{C}_{60}$ and $\mathrm{C}_{84}$ and their interactions with the substrate}

Multi-layers of both $\mathrm{C}_{60}$ s and $\mathrm{C}_{84} \mathrm{~s}$ on $\mathrm{Si}$ crystallize in the fcc structure of the bulk at room temperature. The mono-layer on $\mathrm{Si}$, on the other hand, shows only local orders depending on the surface structure of substrate. On the $\mathrm{Si}(111)$ surface, $\mathrm{C}_{60}$ s order nearly in a close-packed structure shown in Fig. 1 by occupying either the corner hole or adatom bridge site in the $7 \times 7$ structure. The reason is that the distances from an adatom bridge site to the next one and from one to the adjacent corner hole are nearly equal to the separation between two $\mathrm{C}_{60} \mathrm{~s}$ in their close-packed arrangement in the bulk. This lattice matching is less achieved in $\mathrm{C}_{84}$ since its diameter is about $10 \%$ larger than that of $\mathrm{C}_{60}$. Hence $\mathrm{C}_{84} \mathrm{~s}$ do not order even locally on the $\mathrm{Si}(111)$ surface. On the $\mathrm{Si}(100)$ surface, $\mathrm{C}_{60}$ s line up along the gap between the two neighboring dimer rows on the $2 \times 1$ structure, and do not form the close-packed arrangement.

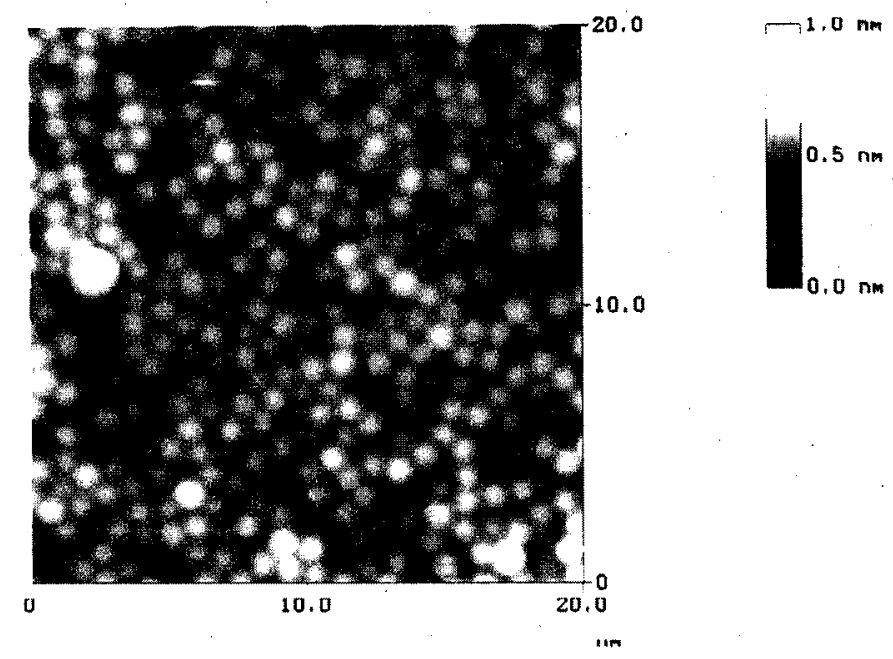

Fig. 1. STM image of the mono-layer of $\mathrm{C}_{60}$ on $\mathrm{Si}(111)$ surface.

The mono-layer of $\mathrm{C}_{60}$ can be formed on $\mathrm{Si}(111)$ by evaporating the right amount of $\mathrm{C}_{60} \mathrm{~s}$ to cover the substrate by a single layer. Another method is to first form a multi-layer and then heat at several hundred degrees Celsius. Since the bottom layer is bound to the substrate more strongly than to the rest of above layers, only the bottom layer remains on the substrate by heating. This method does not yield ordered mono-layer films in the case of $\mathrm{C}_{84}$ because the bottom layer is less ordered and bound on the substrate compared with $\mathrm{C}_{60}$.

\section{Chemical reaction induced by heating}

Heating to higher temperatures induces chemical reaction with the substrate. If the sample is heated to $700^{\circ} \mathrm{C}$ for five minutes and cooled down to room temperature, our STM images show some internal structures of $\mathrm{C}_{60}$ in a twofold symmetry as shown in Fig. 2. At room temperature in the bulk phase or multi-layer, $\mathrm{C}_{60} \mathrm{~s}$ 

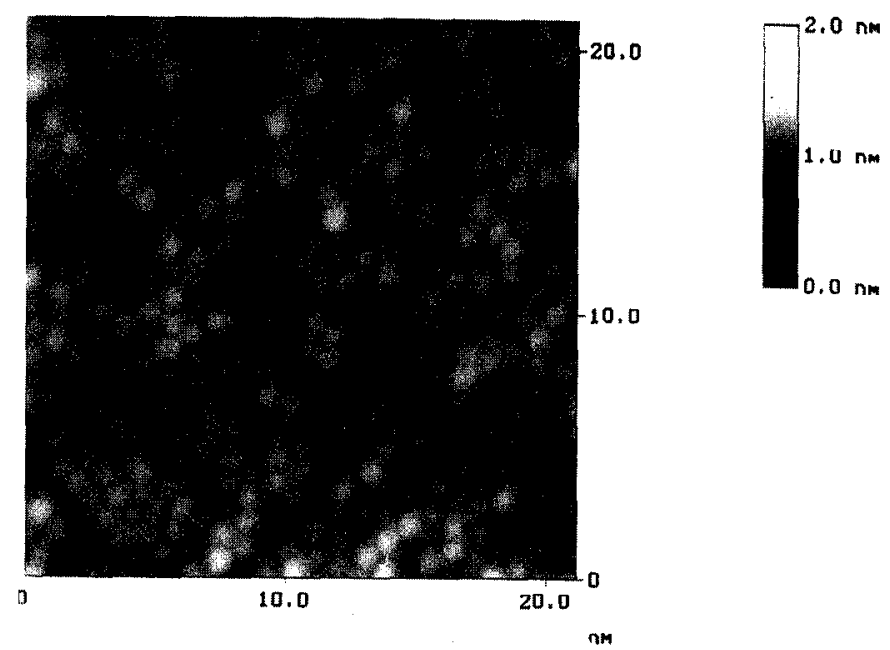

Fig. 2. STM image of the mono-layer of $\mathrm{C}_{60}$ on $\mathrm{Si}(111)$ surface heated at $700^{\circ} \mathrm{C}$.

may be rotating about their lattice site. This rotational motion prevents the internal structure of $\mathrm{C}_{60}$ or $\mathrm{C}_{84}$ to appear in the STM image. The observation of the internal structure in a $\mathrm{C}_{60}$ indicates that the heating of the sample to $700^{\circ} \mathrm{C}$ induces chemical reaction of the $\mathrm{C}_{60}$ with its neighbors or with the substrate and its rotational motion stops. The internal structure appearing in the STM image, then, reflects the symmetry and orientation of $\mathrm{C}_{60}$ with respect to the substrate. The twofold symmetry implies that the $\mathrm{C}_{60}$ is oriented to show one of its double bonds located at the center of the image because the double bond is parallel to the twofold axis. In this orientation, another double bond on the opposite side of icosahedron is facing to the substrate. The STM images in Fig. 2, therefore, indicates that some of $\mathrm{C}_{60}$ s showing twofold symmetry are reacting with the $\mathrm{Si}$ at the double bond site.

Heating above $700^{\circ} \mathrm{C}$ induces chemical reaction between $\mathrm{C}_{60}$ s and $\mathrm{Si}$ substrate to form a $\mathrm{SiC}$ layer on the substrate. The progress of this reaction was depicted by STM and monitored by observing SiC surface phonon with HREELS. Figure 3 shows the results. The loss peaks at $65 \mathrm{meV}$ and in the vicinity of $150 \mathrm{meV}$ are due to vibrational modes of $\mathrm{C}_{60}$ s. After the sample surface is heated above $800^{\circ} \mathrm{C}$, a new peak begins to appear near $95 \mathrm{meV}$ and shifts to $116 \mathrm{meV}$ at $1100^{\circ} \mathrm{C}$. The intensity also increases by orders of magnitude with temperature. This vibrational mode is attributed to a bond formation between $\mathrm{C}$ and $\mathrm{Si}$. The peak value of $116 \mathrm{meV}$ at $1100^{\circ} \mathrm{C}$ is in good agreement with that of the surface phonon of $\mathrm{SiC}$ films. At $800^{\circ} \mathrm{C}$, the $\mathrm{STM}$ measurement still shows clear image of $\mathrm{C}_{60}$. At $1100^{\circ} \mathrm{C}$, on the other hand, it shows an image of SiC lattice. Hence, the frequency shift is interpreted as the gradual bond change from $\mathrm{Si}-\mathrm{C}_{60}$ to the pure $\mathrm{Si}-\mathrm{C}$ as the temperature is raised. On the $\mathrm{Si}(111)$ surface, the peak intensity increases steeply near $870^{\circ} \mathrm{C}$ and tends to saturate above. At this temperature, the image of $\mathrm{C}_{60}$ disappeared. This temperature coincides with the phase transition of the substrate surface structure from $7 \times 7$ to $1 \times 1$. 


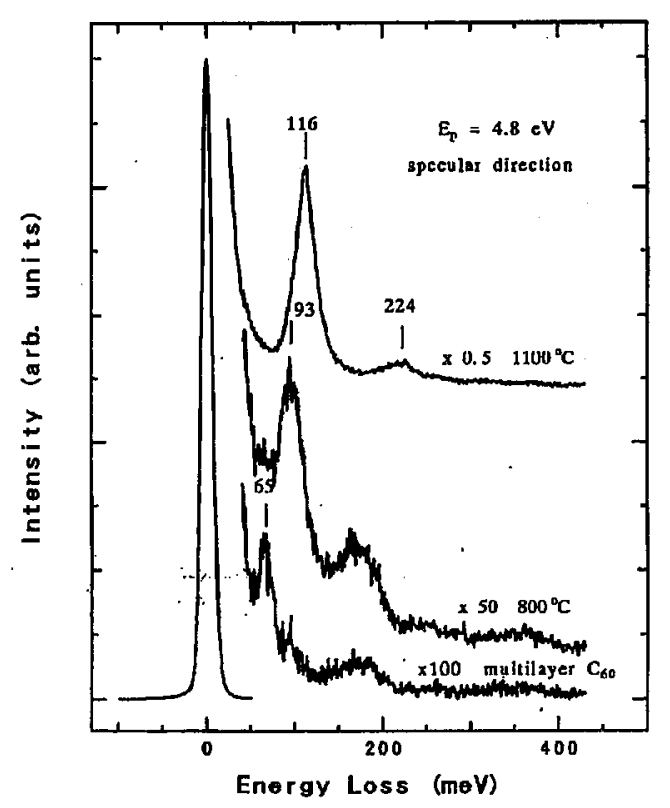

Fig. 3. HREELS spectra of $\mathrm{C}_{60}$ film at different temperatures.

On the $\mathrm{Si}(100)$ surface, the peak intensity exhibits a gradual increase from $650^{\circ} \mathrm{C}$ to $1100^{\circ} \mathrm{C}$ without abrupt change. At $1100^{\circ} \mathrm{C}$, it becomes comparable to the case of $\mathrm{Si}(111)$. The $\mathrm{Si}(100)$ shows $2 \times 1$ surface structure at room temperature. Above $600^{\circ} \mathrm{C}$, the surface structure exhibits many defects which increase with increasing temperature without showing definite structural transitions. Our experimental results, therefore, indicate that the chemical reaction of $\mathrm{C}_{60}$ depends sensitively on the surface structure of $\mathrm{Si}$ substrate. The reactivity appears to be higher for structures having more chemically active sites such as dangling bonds of Si on the surface.

\section{Multi-layer film and laser irradiation effect}

In contrast with the mono-layer film, the multi-layer of $\mathrm{C}_{60}$ and $\mathrm{C}_{84}$ exhibits a well-ordered close-packed structure. The separation between the nearest neighbor $\mathrm{C}_{60}$ is $1.02 \mathrm{~nm}$ and that between two $\mathrm{C}_{84}$ is $1.12 \mathrm{~nm}$. Figure 4 shows an STM image of $\mathrm{C}_{84}$. Absence of any internal structure indicates that these clusters may be rotating at their lattice sites.

The laser irradiation on cluster arrays of $\mathrm{C}_{60}$ and $\mathrm{C}_{84}$ induces pinning of their rotational motions in the layer leading to a variety of local patterns in the scanning tunneling images similar to the case of heating shown in Fig. 3. Figure 5 shows an example of images obtained by irradiating a $\mathrm{C}_{84}$ film by Ar-ion laser of $514.5 \mathrm{~nm}$ up to $10 \mathrm{~W} / \mathrm{cm}^{2}$. It shows two- and threefold symmetries in the image of $\mathrm{C}_{84}$. Threefold symmetry implies that one of the hexagons is oriented to the center of the image of $\mathrm{C}_{84}$.

Some orientational orderings of $\mathrm{C}_{60} \mathrm{~s}$ and $\mathrm{C}_{84} \mathrm{~s}$ exhibit highlighted regions extending towards their neighbors forming a group of clusters looked as if they 

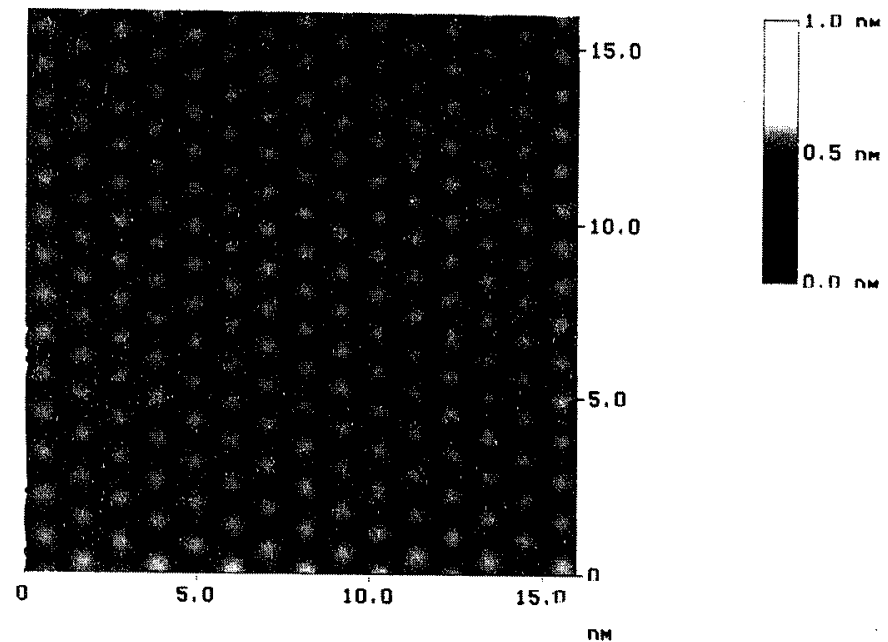

Fig. 4. STM image of multi-layer of $\mathrm{C}_{84}$ on $\mathrm{Si}(111)$ surface.
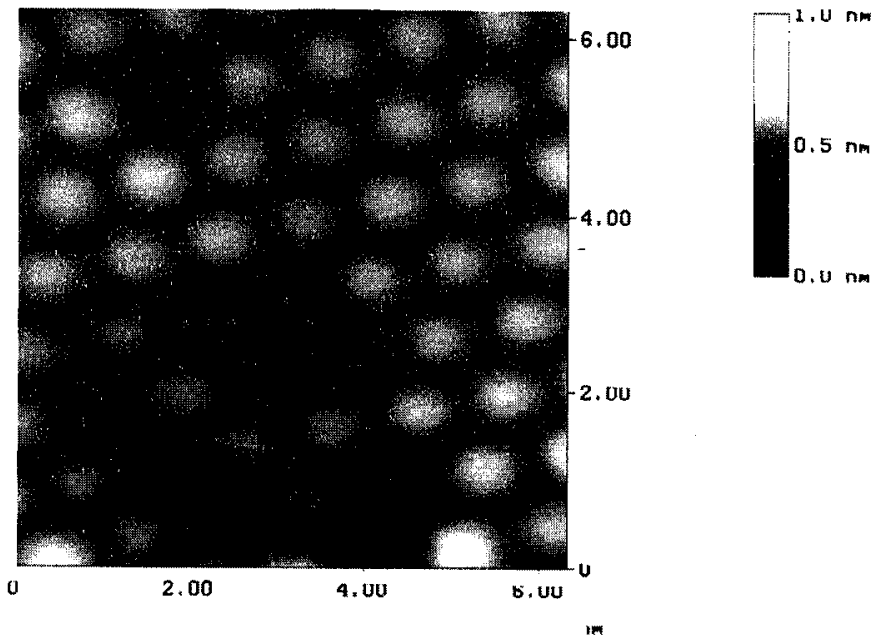

Fig. 5. STM image of multi-layer of $\mathrm{C}_{84}$ on $\mathrm{Si}(111)$ surface after laser irradiation.

are connected to each other in the image. The region extends more for higher positive bias voltages with respect to the tip. This result is interpreted that the laser irradiation produces local chemical bonds which are covalent and their higher empty electronic states extend more toward neighbors.

\section{Summary}

Variety of nanometer scale structures are produced by heating and laser irradiation of $\mathrm{C}_{60}$ and $\mathrm{C}_{84}$ films on $\mathrm{Si}$ substrates, which induces interactions between carbon clusters, $\mathrm{C}_{60}$ or $\mathrm{C}_{84}$, and between carbon clusters and substrates. 
Our combined measurements with STM and HREELS reveal that such structural modifications are possible only through cluster-substrate interaction. These structural modifications are associated with the change in the local electronic structure in nanometer scale. The local electronic structure exhibits electronic properties different from their neighbors and may be used as an opto-electronic function in nanometer scale.

\section{Acknowledgments}

We thank Prof. J. Raułuszkiewicz (Polish Academy of Science), Prof. S. Szuba (Poznań University of Technology) and Dr. K. Karpierz (University of Warsaw) for valuable discussions. This work was supported by CREST of Japan Science and Technology Institute.

\section{References}

[1] C.-W. Hu, A. Kasuya, A. Wawro, S. Suto, Y. Nishina, Appl. Phys. Lett. 68, 1240 (1956).

[2] S. Suto, A. Kasuya, C.-W. Hu, A. Wawro, T. Sakamoto, T. Wakita, T. Goto, Y. Nishina, J. Mater. Sci. Eng. A 217, 34 (1996).

[3] R. Czajka, A. Kasuya, A. Wawro, N. Horiguchi, Y. Nishina, Surf. Rev. Lett. 3, 927 (1996). 